\title{
De-escalation of Axillary Surgery in the Neoadjuvant Chemotherapy (NACT) Setting for Breast Cancer: Is it Oncologically Safe?
}

\author{
UMAR WAZIR $^{1}$ and KEFAH MOKBEL ${ }^{1,2}$ \\ ${ }^{1}$ London Breast Institute, Princess Grace Hospital, London, U.K.; \\ ${ }^{2}$ Department of General Surgery, Khyber Teaching Hospital, Peshawar, Pakistan
}

\begin{abstract}
Background/Aim: The treatment of breast cancer has progressed considerably over the years, with a significant de-escalation from radical mastectomies to the current paradigm of breast conserving surgery (BCS) and neoadjuvant chemotherapy (NACT). We aimed to appraise the literature regarding the feasibility of de-escalation of treatment of axillary disease in the context of NACT. Materials and Methods: We appraised studies and guidelines published regarding this topic and discussed them in this mini-review. Results and Conclusion: The SNB following NACT is oncologically safe in patients with clinically node negative disease and in patients with biopsy proven axillary node involvement at presentation provided that the dual technique is used and the clipped pathological node is harvested.
\end{abstract}

The treatment of breast cancer has come a long way since the days of Halsted and Patey $(1,2)$, with a consistent trend towards de-escalation from radical procedures towards the current norm of breast conserving surgery and neoadjuvant chemotherapy (NACT) (3). Whilst this historic trend has been well-recognised in the context of oncological resection, de-escalation in the treatment of axillary disease has been less uniform. Whilst the previous orthodoxy of complete axillary lymph node dissection (cALND) has given way to a more conservative approach determined by sentinel node status, the road ahead with regards to treatment of axillary

This article is freely accessible online.

Correspondence to: Prof Kefah Mokbel, London Breast Institute, the Princess Grace Hospital, 45 Nottingham Place, London W1U 5NY, U.K. Tel: +44 2079082040. e-mail: kefah.mokbel@hotmail.com

Key Words: Breast cancer, neo-adjuvant chemotherapy, sentinel node biopsy, axillary disease, review. disease in breast cancer has been subject to much debate. One plank of this debate has been the management of the axilla after NACT. In this mini-review, we endeavour to appraise the current literature regarding this subject and hopefully draw clinically relevant conclusions.

\section{Current Evidence Outside NACT}

There is a level I evidence from randomised controlled trials that not removing all axillary lymph nodes containing metastasis does not compromise overall survival (OS). In the recently reported Z011 trial, there was no statistically significant difference in clinical outcomes between patients randomised to cALND following a positive sentinel node biopsy and those randomised to observation only. A $27.3 \%$ of patients undergoing cALND had macro-metastasis. Since the two groups were matched and are the result of randomisation, then a similar proportion of patients who underwent observation only would have metastatic disease in the axillary lymph nodes (4). Both groups had radiation therapy (RT) to the breast, which would have included the lower axilla to a variable degree and RT was considered as one possible explanation for this similar clinical outcome. However, this does not alter the fact that CALND to remove all positive lymph-nodes did not translate into a clinical outcome benefit.

Further evidence to support this observation can be derived from the initial sentinel node biopsy trials where patients were randomised to sentinel node biopsy (SNB) only if the sentinel node was negative for malignancy or axillary node dissection if the sentinel node biopsy was positive for malignancy. It is well recognised that the SNB procedure is associated with a false negative rate (FNR) in the region of $10 \%$, and therefore those patients randomised to observation only following a false negative SNB would have axillary lymph nodes containing metastatic disease, however, this did not compromise their overall or disease-free survival (DFS). 
In the first such randomised trials, the recurrence and mortality events were in fact lower in the SNB group compared with the cALND group, although this difference was not statistically significant $(5,6)$.

The ALMANAC trial confirmed that the omission of complete axillary dissection when the SNB is negative results in less morbidity and greater quality of life in addition to cost-effectiveness (7).

The trial also confirmed the results from earlier studies that there was no difference in the incidence of recurrence between the SNB group and the cALND group. The equivalence in oncological outcome was also confirmed in the B 32 randomised controlled trial (8).

Therefore, there is clear evidence that the omission of surgical removal of non-sentinel nodes containing small volume disease does not compromise OS. This is consistent with the notion that invasive breast cancer is usually a systemic disease at initial diagnosis (9). This concept has been recently supported further by the findings of genomic profiling and circulating tumour cells and tumour DNA in the peripheral blood (10).

Since then de-escalation of axillary surgery has expanded worldwide on the basis that the SNB is a staging procedure and provided that adjuvant systemic therapy and radiation therapy are used appropriately according to tumour biology, then additional axillary surgery would not improve OS.

\section{Regional Node Irradiation as the Only Therapy After Positive SNB}

Furthermore, regional node irradiation (RNI) without cALND did not increase the risk of axillary failure in selected patients with early-stage invasive breast cancer (cT $\leq 3 \mathrm{~cm}, \mathrm{cN} 0$ ) and $\mathrm{pN} 1(\mathrm{sn})$. In this randomised trial, $38.5 \%$ of those assigned to the cALND group had further lymph-node involvement and therefore, a similar number was expected in the RNI group (11).

Similar results were observed in the AMAROS trial where the incidence of additional involved lymph-nodes in the axillary node dissection group was $33 \%$. Although the OS was similar in both groups, however, the initial recurrence was higher in the RNI group without compromising overall survival. Furthermore, the incidence of lymphoedema was significantly lower in the RNI group (12).

\section{Is the SNB a Valid Alternative to cALND in the Context of NACT?}

cNO breast cancer. Encouraged by the evidence discussed above, de-escalation of axillary surgery was expanded to the neoadjuvant setting. A recent meta-analysis of 16 studies including approximately 1,500 patients, confirmed that the SNB is technically feasible and sufficiently accurate for staging the axilla in initially clinically node-negative (cN0) breast cancer after NACT (13). The authors calculated a pooled identification rate of $96 \%$ and false negative rate of $6 \%(95 \%$ confidence interval $=3-8 \%)$. The oncological safety of the SNB in this setting derived further support from clinical outcome analysis after adequate clinical follow up. In a retrospective analysis of cN0, T1-T3 patients who underwent SNB after NACT $(n=575)$ or first-line surgery $(n=3,171)$, nodal recurrence was $1.2 \%$ in the NACT group, with no difference in disease-free or overall survival between groups. The FNR was $5.9 \%$ (11). The incidence of axillary recurrence following a negative SNB after NACT was reported to be as low as $0.24 \%$ in patients with $\mathrm{cN} 0$ disease (14).

Therefore, the SNB has become the standard of care after NACT in patients with cNO disease despite the fact that a small percentage of patients would have undetected residual disease in non-sentinel nodes thus, potentially raising the possibility of adjuvant systemic under-treatment in patients with HER2 positive and triple negative breast cancer (TNBC) where residual disease can be used to guide the use of further adjuvant systemic therapy, such as capecitabine for TNBC (15) and TD-M1 for HER2 positive disease (16). However, the risk of omitting adjuvant chemotherapy in patients undergoing initial breast cancer surgery including SNB is similar since the FNR is less than $10 \%$. Nevertheless, no compromise of oncological outcome was demonstrated in this setting.

cN1 breast cancer. We have recently reported through a meta-analysis, that in patients $(n=3398)$ presenting with biopsy proven axillary lymph-node involvement and undergoing NACT, the SNB is a valid alternative to cALND with a FNR of $13 \%$ and identification rate of $91 \%$ (17). Subgroups analysis showed that the FNR can be decreased to less than $10 \%$ by identifying three or more SLNs, adding patent blue dye in a dual-mapping technique, marking the metastatic lymph node with a clip before NACT and then removing it, and using immunohistochemistry (17-19). The inclusion/addition of the clipped node to the SNB can achieve an FNR of as low as $2 \%(17,20)$. For patients with initially involved nodes, with negative SNB after NACT, no lympho-vascular invasion and a remaining breast tumour size up to $5 \mathrm{~mm}$, the risk of a positive cALND was reported to be $3.7 \%$, regardless of the number of SLNs removed (15).

Tailoring adjuvant systemic therapy following NACT does not only depend upon the axillary node status, but also on the presence of residual disease in the breast. In a recent analysis of 30,821 patients with cT1/cT2 N0/N1 breast cancer treated with NACT and surgical resection, the incidence of nodal positivity in the presence of breast pathological complete response (pCR) was found to be $30.5 \%$ for ER+/HER2-ve, $14.1 \%$ for TNBC and $12.4 \%$ for 
HER2+ve disease (21). The B arm of the Sentina trial (in press) will show that only $1.2 \%$ of TNBC patients and $0.5 \%$ of HER2 positive patients had residual axillary disease in case of a breast pCR. For patients with ER+/HER2-ve disease, the residual disease pathology is very unlikely to alter adjuvant treatment, which would consist usually of optimal endocrine therapy.

Assuming an FNR of $10 \%$ implies that the risk of omitting adjuvant TD-M1 in patients with HER2 positive disease achieving breast pCR would be $1.24 \%$, and the risk of omitting adjuvant capecitabine in patients with TNBC achieving breast pCR would be $1.4 \%$. For TNBC, the absolute overall survival benefit of adjuvant capecitabine is $5.6 \%$ (16). For HER2 positive disease, the absolute benefit of adjuvant TD-M1 in terms of DFS as a surrogate marker of OS was reported to be $5.4 \%$ (19).

These figures indicate that the probability of compromising OS or distant DFS is approximately 1 in 2,000 if complete axillary dissection is omitted. However, this probability would be lower with an FNR below $10 \%$. Since including the clipped node in axillary staging post NACT is becoming standard practice, the probability of oncological compromise would be around 1 in 10,000 assuming an FNR of $2 \%$ (20). Such a low risk does not justify a more invasive surgery that has been demonstrated to increase morbidity and cost and compromise patient quality of life. The recent advent of wireless localisation systems has facilitated accurate marking and localisation of the biopsy proven lymph-node by deploying the marker at the time of biopsy (22).

\section{Conclusion}

The SNB following NACT is oncologically safe in patients with clinically node negative breast cancer and in patients with biopsy proven axillary node involvement at initial presentation provided that the dual technique is used and the clipped pathological node is harvested.

\section{Conflicts of Interest}

The Authors do not have any conflicts of interest to declare in relation to this article.

\section{Authors' Contributions}

KM drafted the initial manuscript. UW performed the literature searches and completed the final draft of the manuscript.

\section{Acknowledgements}

This work was made possible by support from the Breast Cancer Hope Foundation, U.K.

\section{References}

1 Halsted W: The results of operations for the cure of cancer of the breast performed at the Johns Hopkins hospital from June 1889 to January 1894. Ann Surg Innov Res 20: 497-555, 1894. PMID: 17860107. DOI: 10.1097/00000658-189407000-00075

2 Patey DH and Dyson WH: The prognosis of carcinoma of the breast in relation to the type of operation performed. Br J Cancer 2(1): 7-13, 1948. PMID: 18863724. DOI: 10.1038/bjc.1948.2

3 Veronesi U, Cascinelli N, Mariani L, Greco M, Saccozzi R, Luini A, Aguilar M and Marubini E: Twenty-year follow-up of a randomized study comparing breast-conserving surgery with radical mastectomy for early breast cancer. N Engl J Med 347(16): 1227-1232, 2002. PMID: 12393819. DOI: 10.1056/ NEJMoa020989

4 Giuliano AE, Ballman KV, McCall L, Beitsch PD, Brennan MB, Kelemen PR, Ollila DW, Hansen NM, Whitworth PW, Blumencranz PW, Leitch AM, Saha S, Hunt KK and Morrow M: Effect of axillary dissection vs no axillary dissection on 10-year overall survival among women with invasive breast cancer and sentinel node metastasis: The acosog z0011 (alliance) randomized clinical trial. JAMA 318(10): 918-926, 2017. PMID: 28898379. DOI: $10.1001 /$ jama.2017.11470

5 Veronesi U, Paganelli G, Viale G, Luini A, Zurrida S, Galimberti V, Intra M, Veronesi P, Robertson C, Maisonneuve P, Renne G, De Cicco C, De Lucia F and Gennari R: A randomized comparison of sentinel-node biopsy with routine axillary dissection in breast cancer. N Engl J Med 349(6): 546-553, 2003. PMID: 12904519. DOI: 10.1056/NEJMoa012782

6 Veronesi U, Viale G, Paganelli G, Zurrida S, Luini A, Galimberti V, Veronesi P, Intra M, Maisonneuve P, Zucca F, Gatti G, Mazzarol G, De Cicco C and Vezzoli D: Sentinel lymph node biopsy in breast cancer: Ten-year results of a randomized controlled study. Ann Surg 251(4): 595-600, 2010. PMID: 20195151. DOI: 10.1097/SLA.0b013e3181c0e92a

7 Mansel RE, Fallowfield L, Kissin M, Goyal A, Newcombe RG, Dixon JM, Yiangou C, Horgan K, Bundred N, Monypenny I, England D, Sibbering M, Abdullah TI, Barr L, Chetty U, Sinnett DH, Fleissig A, Clarke D and Ell PJ: Randomized multicenter trial of sentinel node biopsy versus standard axillary treatment in operable breast cancer: The almanac trial. J Natl Cancer Inst 98(9): 599-609, 2006. PMID: 16670385. DOI: 10.1093/jnci/djj158

8 Krag DN, Anderson SJ, Julian TB, Brown AM, Harlow SP, Costantino JP, Ashikaga T, Weaver DL, Mamounas EP, Jalovec LM, Frazier TG, Noyes RD, Robidoux A, Scarth HM and Wolmark N: Sentinel-lymph-node resection compared with conventional axillary-lymph-node dissection in clinically nodenegative patients with breast cancer: Overall survival findings from the nsabp b-32 randomised phase 3 trial. Lancet Oncol 11(10): 927-933, 2010. PMID: 20863759. DOI: 10.1016/S14702045(10)70207-2

9 Leone BA, Leone J and Leone JP: Breast cancer is a systemic disease rather than an anatomical process. Breast Cancer Res Treat 161(3): 619, 2017. PMID: 28070768. DOI: 10.1007/ s10549-017-4104-0

10 Bidard FC, Proudhon C and Pierga JY: Circulating tumor cells in breast cancer. Mol Oncol 10(3): 418-430, 2016. PMID: 26809472. DOI: 10.1016/j.molonc.2016.01.001

11 Hunt KK, Yi M, Mittendorf EA, Guerrero C, Babiera GV, Bedrosian I, Hwang RF, Kuerer HM, Ross MI and Meric- 
Bernstam F: Sentinel lymph node surgery after neoadjuvant chemotherapy is accurate and reduces the need for axillary dissection in breast cancer patients. Ann Surg 250(4): 558-566, 2009. PMID: 19730235. DOI: 10.1097/SLA.0b013e3181b8fd5e

12 Donker M, van Tienhoven G, Straver ME, Meijnen P, van de Velde CJH, Mansel RE, Cataliotti L, Westenberg AH, Klinkenbijl JHG, Orzalesi L, Bouma WH, van der Mijle HCJ, Nieuwenhuijzen GAP, Veltkamp SC, Slaets L, Duez NJ, de Graaf PW, van Dalen T, Marinelli A, Rijna H, Snoj M, Bundred NJ, Merkus JWS, Belkacemi Y, Petignat P, Schinagl DAX, Coens C, Messina CGM, Bogaerts J and Rutgers EJT: Radiotherapy or surgery of the axilla after a positive sentinel node in breast cancer (eortc 10981-22023 amaros): A randomised, multicentre, open-label, phase 3 non-inferiority trial. Lancet Oncol 15(12): 1303-1310, 2014. PMID: 25439688. DOI: $10.1016 / \mathrm{s} 1470-2045(14) 70460-7$

13 Geng C, Chen X, Pan X and Li J: The feasibility and accuracy of sentinel lymph node biopsy in initially clinically node-negative breast cancer after neoadjuvant chemotherapy: A systematic review and meta-analysis. PLoS One 11(9): e0162605, 2016. PMID: 27606623. DOI: 10.1371/journal.pone.0162605

14 Classe JM, Loaec C, Gimbergues P, Alran S, de Lara CT, Dupre PF, Rouzier R, Faure C, Paillocher N, Chauvet MP, Houvenaeghel G, Gutowski M, De Blay P, Verhaeghe JL, Barranger E, Lefebvre C, Ngo C, Ferron G, Palpacuer C and Campion L: Sentinel lymph node biopsy without axillary lymphadenectomy after neoadjuvant chemotherapy is accurate and safe for selected patients: The ganea 2 study. Breast Cancer Res Treat 173(2): 343-352, 2019. PMID: 30343457. DOI: 10.1007/s10549-018-5004-7

15 Masuda N, Lee SJ, Ohtani S, Im YH, Lee ES, Yokota I, Kuroi K, Im SA, Park BW, Kim SB, Yanagita Y, Ohno S, Takao S, Aogi K, Iwata H, Jeong J, Kim A, Park KH, Sasano H, Ohashi $\mathrm{Y}$ and Toi M: Adjuvant capecitabine for breast cancer after preoperative chemotherapy. N Engl J Med 376(22): 2147-2159, 2017. PMID: 28564564. DOI: 10.1056/NEJMoa 1612645

16 Tee SR, Devane LA, Evoy D, Rothwell J, Geraghty J, Prichard RS and McDermott EW: Meta-analysis of sentinel lymph node biopsy after neoadjuvant chemotherapy in patients with initial biopsy-proven node-positive breast cancer. Br J Surg 105(12): 1541-1552, 2018. PMID: 30311642. DOI: 10.1002/bjs.10986

17 El Hage Chehade H, Headon H, El Tokhy O, Heeney J, Kasem $\mathrm{A}$ and Mokbel $\mathrm{K}$ : Is sentinel lymph node biopsy a viable alternative to complete axillary dissection following neoadjuvant chemotherapy in women with node-positive breast cancer at diagnosis? An updated meta-analysis involving 3,398 patients. Am J Surg 212(5): 969-981, 2016. PMID: 27671032. DOI: 10.1016/j.amjsurg.2016.07.018
18 Cavalcante FP, Millen EC, Zerwes FP and Novita GG: Role of axillary surgery after neoadjuvant chemotherapy. JCO Glob Oncol 6: 238-241, 2020. PMID: 32073911. DOI: 10.1200/JGO.19.00351

19 von Minckwitz G, Huang CS, Mano MS, Loibl S, Mamounas EP, Untch M, Wolmark N, Rastogi P, Schneeweiss A, Redondo A, Fischer HH, Jacot W, Conlin AK, Arce-Salinas C, Wapnir IL, Jackisch C, DiGiovanna MP, Fasching PA, Crown JP, Wulfing P, Shao Z, Rota Caremoli E, Wu H, Lam LH, Tesarowski D, Smitt M, Douthwaite H, Singel SM, Geyer CE Jr. and Investigators $\mathrm{K}$ : Trastuzumab emtansine for residual invasive her2-positive breast cancer. N Engl J Med 380(7): 617-628, 2019. PMID: 30516102. DOI: 10.1056/NEJMoa1814017

20 Caudle AS, Yang WT, Krishnamurthy S, Mittendorf EA, Black DM, Gilcrease MZ, Bedrosian I, Hobbs BP, DeSnyder SM, Hwang RF, Adrada BE, Shaitelman SF, Chavez-MacGregor M, Smith BD, Candelaria RP, Babiera GV, Dogan BE, Santiago L, Hunt KK and Kuerer HM: Improved axillary evaluation following neoadjuvant therapy for patients with node-positive breast cancer using selective evaluation of clipped nodes: Implementation of targeted axillary dissection. J Clin Oncol 34(10): 1072-1078, 2016. PMID: 26811528. DOI: 10.1200/JCO.2015.64.0094

21 Barron AU, Hoskin TL, Day CN, Hwang ES, Kuerer HM and Boughey JC: Association of low nodal positivity rate among patients with erbb2-positive or triple-negative breast cancer and breast pathologic complete response to neoadjuvant chemotherapy. JAMA Surg 153(12): 1120-1126, 2018. PMID: 30193375. DOI: 10.1001/jamasurg.2018.2696

22 Gera R, Tayeh S, Al-Reefy S and Mokbel K: Evolving role of magseed in wireless localization of breast lesions: Systematic review and pooled analysis of 1,559 procedures. Anticancer Res 40(4): 1809-1815, 2020. PMID: 32234869. DOI: 10.21873/ anticanres.14135
Received June 13, 2020

Revised July 23, 2020

Accepted July 24, 2020 